\title{
A TERRA XAVANTE (MAIS UMA VEZ) NO CAMINHO DA MINERAÇÃO ${ }^{1}$ \\ LAS TIERRAS XAVANTE (UNA VEZ MÁS) EN EL CAMIÑO DE LA MINERACIÓN
}

THE XAVANTE TERRITORY (ONE MORE TIME) ON THE MINING WAY

Renan Andreosi Salles de Oliveira ${ }^{2}$

\begin{abstract}
RESUMO: O presente trabalho tem por objetivo analisar as principais consequências da instalação de atividades econômicas de infraestrutura em Terras Indígenas (TI) ou em áreas próximas, convencionadas como Áreas de Influência Direta (AID). A proposta se concentra sobre as atividades de mineração planejadas pela iniciativa público-privada ou apenas privada para a sub-bacia do rio das Mortes, inserida na bacia do Araguaia, nordeste do estado do Mato Grosso, Brasil. A análise procura apresentar as latentes pressões que o povo Xavante pode sofrer com o aumento brusco da presença de não índios nas áreas próximas à Reserva e verificar quais as possíveis consequências dessa rápida mudança em seu hábitat. Noutras palavras, objetiva-se mostrar que a intensificação dessas pressões sobre a TI e sobre os Xavante não apenas implica o agravamento do quadro de desagregação sociocultural, como também pode desencadear conflitos fundiários fora dos limites da Reserva que, fatalmente, venham a se encerrar nas aldeias.
\end{abstract}

Palavras chave: Xavante, mineração, território, cerrados, conflitos.

RESUMEN: El presente trabajo tiene como objetivo analizar las principales consecuencias de la instalación de actividades económicas de infraestructura en las Tierras Indias (TI) o en áreas próximas, establecidas como Áreas de Influencia Directa (AID). La propuesta se concentra sobre las actividades de minería planeadas por la iniciativa público-privada o apenas privada para la sub-cuenca del Rio das Mortes, inserida en la cuenca del Araguaia, nordeste de Mato Grosso, Brasil. El análisis busca presentar las presiones latentes que el pueblo Xavante puede sufrir con el alza brusco de la presencia de no indios en las áreas próximas de la Reserva y verificar cuales serán las posibles consecuencias de ese cambio rápido en su hábitat. O sea, uno desea mostrar que la intensificación de esas presiones sobre la TI y sobre los Xavante implica

\footnotetext{
${ }^{1}$ Este artigo foi elaborado a partir do Trabalho de Graduação Individual (TGI) em Geografia apresentado junto ao Departamento de Geografia da FFLCH-USP, em 2013, sob a orientação da professora Dr. a Valéria de Marcos.

${ }^{2}$ Mestrando no Programa de Pós-Graduação em Geografia do Departamento de Geografia da Universidade Estadual Paulista (Unesp) - Campus Rio Claro. E-mail: <renan.andreosi@gmail.com>.
} 
no solamente en el agravo del cuadro de desagregación sociocultural sino también desarrollar conflictos de tierras que pueden comenzar fuera de los límites de la Reserva y lamentablemente terminar en las aldeas.

Palabras Ilave: Xavante, minería, territorio, cerrados, conflicto.

ABSTRACT: The present monography aims at analyzing the main consequences of the settlement of economical infra-structure activities in Indian Lands (IL) or in nearby areas, conventionalized as Areas of Direct Influence (ADI). The proposal concentrates over the mining activities planned by the public-private or private only sectors for the Rio das Mortes sub-basin, inserted in the Araguaia basin, northeast of Mato Grosso state, Brazil. The analysis aims at presenting the latent pressures the Xavante territory may suffer due to the sudden rise of non-indian presence in the areas nearby the Reservation and verify the possible consequences of that fast change in its habitat. In other words, one intends to show that the enlargement of those pressures upon the IL (Indian Land), and upon the Xavante people not only implies the worsening of sociocultural disaggregation, but it can also trigger land disputes which may begin outside the Reservation and fatally end up in the Xavante territory.

Key words: Xavante, mining, territory, cerrados, conflict.

\section{Introdução}

O presente artigo tem por objetivo analisar as principais consequências da instalação de atividades econômicas de mineração em Terras Indígenas (TI) ou em áreas próximas, convencionadas como Áreas de Influência Direta (AID).

A proposta se concentra sobre as atividades de mineração planejadas pela iniciativa público-privada ou apenas privada para a sub-bacia do rio das Mortes, inserida na bacia do Araguaia, no nordeste do estado do Mato Grosso, Brasil.

O recorte espacial para essa análise localiza-se entre o médio e baixo curso do rio das Mortes, entre as divisas dos municípios de Barra do Garças, General Carneiro, Nova Xavantina e Novo São Joaquim, tomando como unidade de recorte territorial principal a Terra Indígena São Marcos (Decreto $6.715 / 1975$ ) ocupada pela etnia Xavante. 
A Terra Xavante (mais uma vez) no caminho da mineração, pp. 105-126.

Mapa 1 - Localização da Terra Indígena (TI) São Marcos, município de Barra do Garças, Mato Grosso, Brasil.
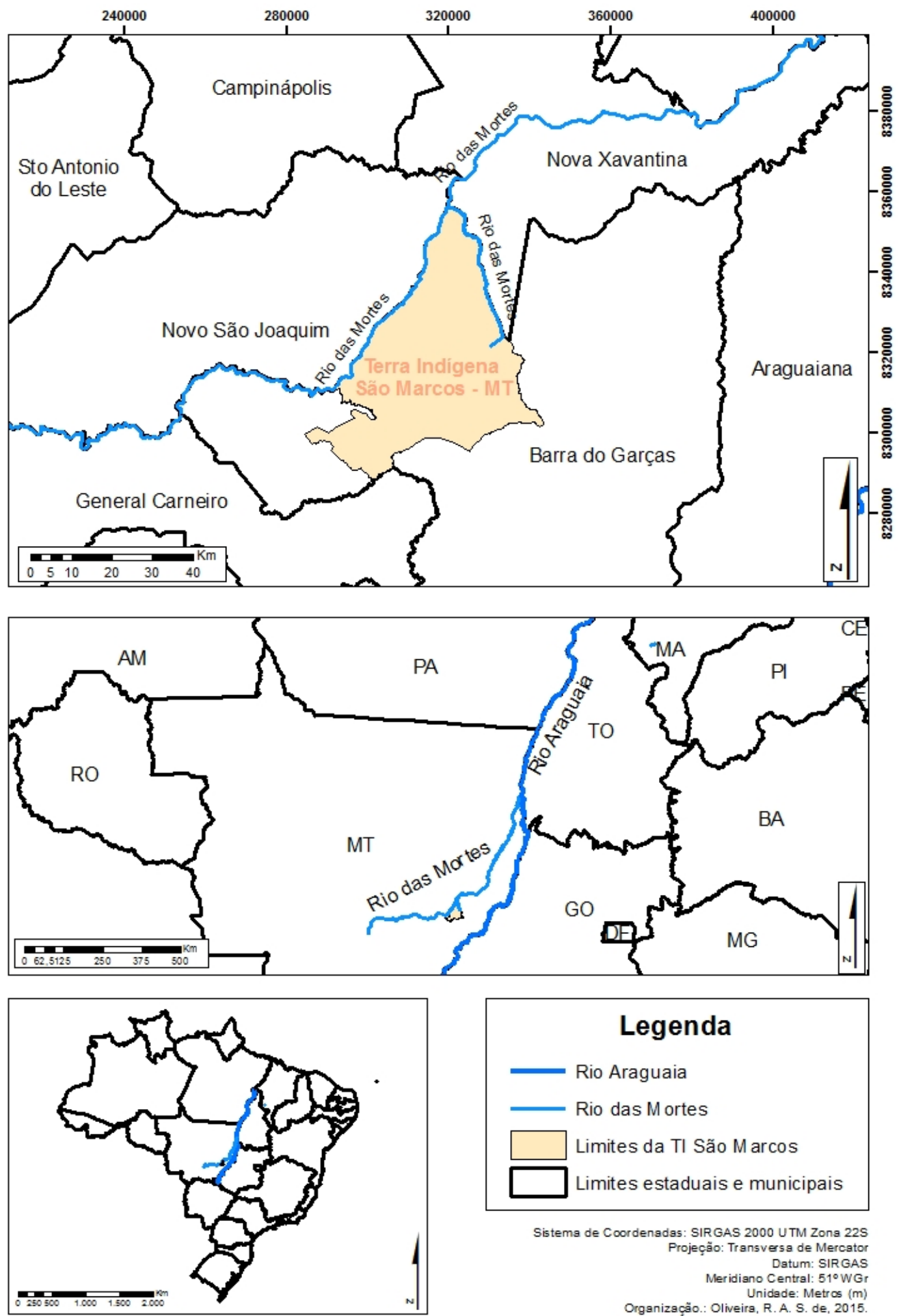
A análise procura apresentar as latentes pressões que o povo Xavante pode sofrer com o aumento brusco da presença de não índios nas áreas próximas à Reserva e verificar quais as possíveis consequências dessa rápida mudança em seu habitat. Noutras palavras, objetiva-se mostrar que a intensificação dessas pressões sobre a TI e sobre os Xavante não apenas implica o agravamento do quadro de desagregação sociocultural, como também pode desencadear conflitos fundiários que, uma vez iniciados fora dos limites da Reserva, possam, fatalmente, se encerrarem nas aldeias.

A escolha do tema se justifica quando se toma ciência de que ao longo de cinco séculos as populações indígenas americanas vêm sofrendo a expropriação de suas terras, sendo massacradas ou subjugadas culturalmente. Durante esse período multiplicaram-se aos milhares os relatos sobre esses choques entre "civilização" e povos indígenas nos quais o ponto de divergência é sempre a disputa pela terra e seus recursos (sendo, inclusive, o próprio indígena considerado como um "recurso" da terra).

A exemplo disso Antônio Carlos Robert Moraes faz a seguinte análise:

Em primeiro lugar, é necessário ter clara a determinação da via colonial do desenvolvimento do capitalismo [...].

Nesse contexto o colonizador desenvolve a ideia da conquista. A mesma teorização teológica que sanciona a apropriação violenta da terra legitima a posse do escravo: a tese da "guerra justa" e do combate ao "infiel" fundamenta a tomada dos lugares e de seus habitantes. Na verdade, o colonizador não estabelece esta distinção, vendo a população das áreas conquistadas como um recurso natural... Assim, o país colonial, fruto de uma expansão que lhe é externa, nasce no bojo de território a conquistar, isto é, sob o signo da violência. (MORAES, 2005, p. 97) 


\title{
A mineração e os povos nativos
}

\begin{abstract}
O índio foi um dos problemas complexos que a administração lusitana enfrentou após iniciada a obra colonizadora, pelo objetivo que se teve em vista de aproveitá-lo como elemento participante desta colonização. (CHAIM, 1983, p. 65)
\end{abstract}

A incapacidade da Coroa portuguesa em ocupar e expandir os limites territoriais de sua colônia na América sem o auxílio dos povos nativos provocou uma série de impasses e dilemas para seus administradores. A utilização do elemento indígena como vetor de entrada e colonização das terras interiores simbolizou um verdadeiro "quebra cabeças" para as administrações metropolitanas.

Os povos nativos, nesse contexto, não poderiam ser apenas "guias dos sertões", mas necessariamente também difusores da "fé cristã", da cultura e soberania portuguesas sobre os territórios percorridos, de forma a criar as bases necessárias para a construção de uma colônia que servisse aos propósitos de acumulação idealizados pelos portugueses (PRADO JUNIOR, 2008).

As descobertas minerais realizadas no século XVIII estabeleceram não só os novos rumos econômicos para a colônia, mas também as novas diretrizes que orientaram as políticas indígenas subsequentes. Mais do que nunca, a participação do indígena na economia colonial se fez necessária e, por isso, foi igualmente necessário criar práticas jurídicas que estivessem em consonância com essas novas diretrizes econômicas.

As Cartas Régias desse período, que discorriam sobre o aprisionamento e redução dos indígenas nas capitanias de Goiás, Mato Grosso, Minas Gerais e São Paulo, são bons exemplos disso quando apontam que seria necessária a utilização da mão de obra indígena tanto nos descobrimentos de novas jazidas quanto em outros serviços relacionados à atividade minerária.

Chaim faz a seguinte observação: 


\begin{abstract}
Essas determinações acompanhariam as mesmas diretrizes da política da Capitania de São Paulo em relação ao índio, muito semelhante às reivindicações feitas anteriormente - em 1725 - [...] no sentido de que os índios administrados passassem aos herdeiros e aos mineradores, e, na falta destes, deveriam ser colocados em aldeias reais, sob a alegação de não poderem prescindir dos mesmos em suas andanças pelo sertão, à cata de ouro. Ficava, portanto, reforçada a condição de semisservidão do índio. (CHAIM, 1983, p. 71 e 72)
\end{abstract}

Nesse período, portanto, as ações contra os povos indígenas se intensificaram, ora através de seu aprisionamento, ora através da sua eliminação, fazendo com que as incoerências das legislações coloniais se tornassem mais evidentes. Mais que isso, a incongruência da política colonial em relação aos povos nativos, juntamente com a "necessidade" de colonização do território e o anseio por minerais preciosos acabaram por criar um quadro social instável, com constante desequilíbrio entre as forças atuantes.

Sebastião José de Carvalho e Mello, Conde de Oeiras, o Marquês de Pombal, foi o responsável por administrar e normatizar qualquer procedimento realizado no interior da colônia em relação aos povos nativos. Na tentativa de impedir arbitrariedades praticadas por colonos no uso da mão de obra indígena segundo interesses pessoais, o marquês de Pombal retomou a política de "redução" com prerrogativas diferentes daquelas idealizadas anteriormente pelos jesuítas, com o objetivo de estimular a inserção das populações indígenas na sociedade colonial segundo os costumes "civilizados".

Assim, a partir de 1750 os "aldeamentos" ganharam novo fôlego, procurando "integrar" o índio de maneira "racional e pacifica" na economia e sociedade coloniais. Os aldeamentos acabaram assumindo um importante papel nas frentes de expansão, especialmente na capitania de Goiás, na qual estavam instalados desde tempos imemoriais os povos indígenas do grupo 
"Akwen", ao qual pertenciam os Xavante (SAMPAIO, $1913^{3}$ e NIMUENDAJÚ, $1944^{4}$ apud DE PAULA, 2007).

Segundo esses autores, os primeiros relatos sobre o grupo Akwen realizados por bandeirantes remetem-se ao século XVIII, quando os mesmos começaram a desbravar o Brasil central e iniciaram os primeiros contatos com as nações dessa região. Acredita-se que o território original desse grupo abrangia os atuais estados de Goiás, Distrito Federal e Tocantins, além de trechos do Maranhão, Piauí, Bahia e Minas Gerais.

A proximidade das terras Akwen com o epicentro da atividade mineraria do período acabou por colocar seu território no caminho das frentes de expansão que buscavam novas jazidas e, consequentemente, colocou esses povos na mira das novas políticas de "integração social" idealizadas por Pombal.

A despeito disso, De Paula observa que todos os povos do grupo Akwen

Foram simultaneamente atingidos pela "guerra de conquista" patrocinada pela Coroa e pelo império através do incentivo direto à organização de bandeiras, apoio às frentes pioneiras de ocupação, parcerias indiretas com missões católicas (jesuítas num primeiro momento e depois capuchinhas) e, por fim, a instalação de presídios militares para os índios da Província de Goiás. (DE PAULA, 2007, p. 178)

As "submissões" dos povos do grupo Akwen segundo relatos de autores como Giaccaria \& Heide (1972) e Ravagnani (1991) aconteceram de maneira gradual e condicionada a inúmeros conflitos, que produziram perdas significativas tanto para os indígenas quanto para os colonos. Esses conflitos, acima de tudo, serviram de um lado para mostrar a insatisfação desses povos em relação às tentativas de inseri-los na política de redução e, de outro, para exibir o poderio bélico dessas nações.

Assim, os Xavante, juntamente com Acroá, Xacriabá, Xerente, Javaé e Kaiapó, pela primeira vez no curso de sua história, "atravessaram" o caminho

\footnotetext{
3 SAMPAIO, Theodoro. "Os Kraôs do Rio Preto no Estado da Bahia". Revista do Instituto Histórico e Geográphico Brasileiro, Rio de Janeiro, tomo 75, parte 1, 1913.

4 NIMUENDAJú, Curt. Mapa etno-histórico de Curt Nimuendajú. Rio de Janeiro: FIBGE, 1981 [1944].
} 
das frentes de expansão da colonização realizadas sob a égide da expansão minerária, e, assim, vivenciaram suas primeiras "submissões" em relação à nascente e crescente sociedade nacional.

\section{A mineração e os Xavante: primeira parte}

Logo que o Ilmo. e Exmo. Senhor Tristão da Cunha Menezes entrou no governo desta capitania de Goiaz, empreendeu civilizar e trazer ao domínio português as nações bárbaras, que tem os seus domicílios nas vizinhanças dos nossos estabelecimentos $[\ldots]$.

$[\ldots]$

Porém, quando se aplicava em descobrir os mais fáceis meios de pôr em execução estes úteis projetos, Ihe chegou a funesta notícia da súbita invasão dos índios Xavantes nas terras contíguas ao Arraial de Crixás (...) continuou nossa bandeira a sua marcha até encontrar os bárbaros que afincadamente rejeitaram todas as propostas de paz, (...) da impossibilidade de trazer à razão aquele gentio indócil e tenaz, mais por uma errada suspeita, que por fereza de gênio, procurou para dar cumprimento as expressas recomendações do excelentíssimo capitão general aprisionar alguns indivíduos daquela rebelde nação... (FREIRE, 1790 apud GOMIDE, 2008, p. 168)

Gomide (2008), ao analisar o relato na íntegra, observa ainda que José Rodrigues Freire reafirma a importância econômica da conquista desses territórios ao deixá-los livres de "bárbaros" e disponíveis à procura e cata do ouro e de outras riquezas minerais, deixando claro o viés econômico dessa empreitada contra os indígenas.

Ainda assim, para o governo da Província, a "submissão", apesar de simbolizar uma importante vitória sobre o gentio, seria apenas a primeira etapa do processo de pacificação, sendo necessário num segundo momento "enfraquecer" o povo Xavante de forma a desestimular ou até inibir insurreições.

A primeira medida adotada nesse sentido foi a fragmentação do grupo em dois aldeamentos distintos, desmantelando as ordens tribais $\mathrm{e}$ dificultando a organização de qualquer tipo de ação ofensiva. O primeiro aldeamento criado foi o de Pedro III, no sítio Carretão, às margens do rio 
A Terra Xavante (mais uma vez) no caminho da mineração, pp. 105-126.

Carretão Grande, e, o segundo, próximo ao rio Crixás, denominado Mossâmedes.

Apesar de ter sido veementemente rechaçada pelos Xavante, a medida acabou se concretizando devido à falta de estrutura do primeiro aldeamento em receber um número tão grande de indígenas. Assim, o fracionamento da população, além de inevitável, atendeu eficientemente aos propósitos idealizados pela Coroa no esfacelamento da coesão Xavante.

A conclusão desse processo realizou-se através da fome, dos maus tratos e das doenças que simbolizaram os meios mais rápidos e eficazes de desagregação e erradicação do povo Xavante no interior dos aldeamentos. Segundo De Paula (2007), uma epidemia de sarampo teria sido a principal causa da morte de grande parcela da população aldeada, fazendo com que, os poucos, remanescentes fugissem para os sertões ainda não ocupados em busca de um recomeço.

O fracasso dos aldeamentos restaurou a instabilidade política e territorial na Província de Goiás e restabeleceu antigos conflitos entre indígenas e colonos, o que exigiu do governo colonial o desenvolvimento de novas políticas de controle dos povos indígenas. Em resposta a essas novas demandas, o governo goiano criou "presídios militares" que tinham a função de abrigar todos aqueles que fossem aprisionados em combate, fossem eles homens, mulheres ou crianças indígenas (GIACCARIA \& HEIDE, 1972; RAVAGNANI, 1991; DE PAULA, 2007; e GOMIDE, 2008).

Uma Carta Régia de 1811 ilustra essa nova política indígena quando afirma que

falho os meios brandos, será preciso empregar a força armada contra o índio, sendo esse recurso, de que se deverá lançar mão, para conter os Apinayé, Xavante, Xerente e Canoeiros, porquanto suposto que os insultos por eles praticados tenham origem no rancor que conservam pelos maus tratos experimentados e partidos de alguns comandantes das aldeias, não resta, presentemente, outro partido, senão intimidá-los e até destruí-los, se necessário for, para evitar os danos que causam. (DE PAULA, 2007, p. 182) 
A política de encarceramento instaurada nesse período construiu cerca de treze presídios só na Província de Goiás, sendo que um desses, foi construído especialmente para abrigar os grupos Xavante e Xerente. Segundo Ravagnani (1991), o presídio militar de Santa Maria do Araguaia tinha por objetivo isolar esses grupos da crescente colonização e da navegação que estava acontecendo na região do rio Araguaia.

O presídio de Santa Maria do Araguaia representou um momento emblemático na história de alguns povos que habitavam o Brasil central, em especial para os Xavante, pois, além de não terem se submetido ao cárcere como forma de resistência, se juntaram a Xerentes e Carajás formando uma coligação de nações indígenas que teve por objetivo atacar o presídio. Segundo Alencastre (1979), ao final da empreitada, no ano de 1813, o presídio de Santa Maria do Araguaia foi destruído, selando assim o destino desses povos que, diante de tal insulto, não mais poderiam habitar as terras do "bico do papagaio" (área da confluência entre os rios Araguaia e Tocantins).

Os anos que se seguiram a esse episódio foram de intensa perseguição e conflitos forçando as etnias coligadas a se dispersarem à procura de novas terras que não estivessem sob a influência colonial. Segundo Gomide (2008), nesse período surgiram diversos relatos sobre a dispersão Xavante pelo Norte de Goiás, numa tentativa de isolamento que invariavelmente fracassou diante da cobiça de colonos que se instalaram nessa porção do território.

A impossibilidade de permanecer em seus territórios ancestrais colocou, portanto, xavantes e xerentes em marcha à procura de novas terras sertão adentro, fazendo com que eles atravessassem o rio Araguaia em direção ao oeste. A respeito disso, De Paula dá o seguinte depoimento:

Segundo os relatos nativos coletados pelos missionários salesianos na fuga das terras goianas, grupos locais xavantes fundaram a aldeia de Dunári ainda na margem Leste do rio Araguaia (denominado pelos Xavante como "Oprè"), mas os brancos voltaram a incomodá-los e eles atravessaram e fundaram uma aldeia da qual não lembram o nome, para, em seguida, atravessarem o rio Cristalino e fundarem a aldeia Maratò'bre. (DE PAULA, 2007, p. 225) 
Assim, entre 1850 e 1890, realizam-se gradualmente os grandes movimentos migratórios da etnia Xavante em direção às terras que atualmente abrigam o estado do Mato Grosso, o que culminou no estabelecimento de três regiões distintas de ocupação na margem oeste do rio Araguaia, entre os rios Cristalino e das Mortes. Esse processo de (re)territorialização no Leste mato-grossense, por sua vez, durou até o primeiro quartel do século XX quando aconteceu - forçosamente - 0 restabelecimento do contato com a sociedade nacional.

\section{A mineração e os Xavante: segunda parte}

A recusa ao contato com a sociedade nacional e a procura por novas terras levaram os Xavante, depois de um longo percurso, a se instalarem no Leste matogrossense. $O$ isolamento almejado se mostrou frágil e breve: novos contatos não tardaram a acontecer e, dessa vez, as mudanças provocadas no modo de vida ancestral Xavante foram profundas e permanentes.

As tentativas de "civilizar" os Xavante durante o século XX decorreram das necessidades de inserção de novas áreas no sistema econômico nacional e da criação de uma reserva de mão de obra que seria necessária à realização de um projeto maior de desenvolvimento idealizado inicialmente na aurora da República, posto em prática durante o Estado Novo com Getúlio Vargas, nas décadas de 1930 e 1940, e mais intensamente durante a Ditadura Militar, após o Golpe de 1964 (DAVIS, 1978; MORAES, 2005).

Davis ilustra as aspirações desenvolvimentistas de Getúlio Vargas quando reproduz o seguinte fragmento de um de seus discursos sobre a importância da colonização das terras interiores:

Nada nos deterá neste movimento que é, no século $X X$, a maior tarefa do homem civilizador: conquistar e dominar os vales das grandes torrentes equatoriais, transformando sua força cega e extraordinária fertilidade em energia disciplinada... (DAVIS, 1978, p. 45) 
Ainda que as novas medidas aparentemente repitam ações e aspirações do passado, como a de permitir o livre acesso às terras com grande potencial econômico através da utilização direta ou indireta da mão de obra indígena, elas apresentam um novo caráter quando não se prestam apenas à realização de uma acumulação primitiva de capital de base colonialista, mas, em vez disso, procuram viabilizar a expansão do capital num outro sistema, o de base capitalista.

Martins ajuda a explicar o novo caráter de apropriação da terra quando afirma que:

[...] a expropriação constitui uma característica essencial do processo de crescimento do capitalismo [...]. O capital só pode crescer, só pode se reproduzir, à custa do trabalho, porque só o trabalho é capaz de criar riqueza. (MARTINS, 1982a, p. 55)

As novas formas de apropriação do espaço nessa perspectiva, segundo Martins, modificam as relações sociais e estabelecem diferentes usos da terra sob os quais a terra assume um caráter de mediadora na produção do lucro, tornando-se terra de negócio, conflitando diretamente com a concepção de terra de subsistência apregoada pelas populações indígenas.

A retomada dos contatos com a nação Xavante durante a primeira metade do século $X X$, sob um ponto de vista capitalista, ocorreu, portanto, sob a égide da expansão do capital num contexto em que era creditado ao Estado a responsabilidade de criar as condições necessárias para a integração de novas áreas à economia.

Dentro desse contexto é que, na década de 1940, Getúlio Vargas idealizou um modelo de ocupação territorial "desenvolvimentista multipolarizado" no qual o Estado não só proveria condições para a colonização, mas, de maneira integrada e simultânea, estimularia a realização de atividades econômicas em todas as regiões do país, em especial no Brasil Central e na Amazônia.

Para a realização dessas medidas, o Estado Novo estabeleceu convênios internacionais de cooperação financeira e tecnológica (em especial 
com os EUA) para a criação de instituições pretensamente modernas que, através de seu know how técnico, pudessem viabilizar a colonização e gestão das áreas interiores. É nesse contexto que nasce, em 1943, por exemplo, a Fundação Brasil Central (FBC), que inicialmente foi resultado de uma parceria para o desenvolvimento da aviação brasileira, mas que rapidamente tornouse um importante "braço" dessa política de colonização e foi uma das grandes responsáveis pela ocupação dos territórios Xavante.

Esse convênio, segundo Davis (1978), consistiu na transferência de tecnologia e capacitação humana, permitindo a construção de pistas de pouso e o rápido desbravamento da porção Central do Brasil (Goiás e Mato Grosso). Por isso, o autor afirma que a FBC passa a desempenhar outras funções, como a de estimular e fomentar a ocupação e realização de atividades econômicas nas áreas desbravadas, o caso, por exemplo, da fundação da Vila de Xavantina nas margens do rio das Mortes, realizada por um dos braços avançados da Fundação, a Expedição Roncador-Xingu (ERX), durante a década de 1940.

A agropecuária e a extração mineral, segundo Vargas, seriam as principais atividades econômicas na inserção dessas novas áreas no sistema econômico nacional, pois, além de vetorizarem significativos contingentes populacionais para as "novas" áreas, elas representariam uma etapa fundamental no processo de industrialização do país, sendo responsáveis pelo fornecimento das matérias-primas necessárias ao desenvolvimento da agroindústria e das indústrias de base.

Assim tem início uma nova "Marcha para o Oeste" que, com duas frentes de expansão distintas, uma agropecuária e outra minerária, criou novas demandas econômicas, justificou os acordos de cooperação técnica, facilitou a entrada de novos capitais estrangeiros e, acima de tudo, permitiu em pouco tempo a ocupação das terras Xavantes. Apesar do desenvolvimento de ambas as frentes acontecer de maneira paralela, os resultados dessas ações produziram mudanças socioambientais simultâneas que acabaram por potencializar os efeitos dessa expansão sobre os territórios das populações indígenas. 
As primeiras evidências desse processo, como afirmado anteriormente, foram os loteamentos e vendas, pelo Governo do Mato Grosso, de porções do território Xavante a empreendedores privados - principalmente paulistas - para a implantação de fazendas de gado bovino logo após a aceitação dos novos contatos nas décadas de 1940 e 1950.

A pecuária se mostrou uma eficiente atividade colonizadora nesse período pois, em pouco tempo, devastou extensas áreas de mata nativa, gerou sérios conflitos agrários e dizimou uma parcela importante do povo Xavante, por meio de embates diretos ou de doenças.

Os conflitos deflagrados no período agravaram-se com a ascensão dos militares ao poder em 1964. Para os novos governantes, o Brasil não podia mais esperar, a "integração" e o crescimento econômico eram necessários e deveriam ser alcançados a qualquer preço, mesmo que o custo disso fosse a degradação dos povos nativos e seus habitats.

A Amazônia, nesse contexto, seria o grande obstáculo à política integracionista proposta pelos militares e, por isso mesmo, foi a região brasileira em que se concentraram os principais programas para 0 crescimento econômico. O desafio que não pôde ser vencido por Getúlio Vargas deveria ser retomado e, com o uso de novas tecnologias, ser transposto pelos militares.

A retomada desse desafio, porém, reavivou um antigo dilema já vivenciado por governos anteriores relacionado aos possíveis modelos de ocupação da Amazônia. Na primeira metade da década de 1970, segundo Fernandes, Welch e Gonçalves (2012), os diferentes modelos de colonização opõem-se através de dois paradigmas distintos.

De um lado, o paradigma da questão agrária, que tem na autonomia camponesa a perspectiva de construção de uma outra sociedade que atenua os problemas estruturais do capitalismo e, de outro, o paradigma do capitalismo agrário que toma as desigualdades como problemas conjunturais que podem ser superados através da inserção da sociedade como um todo no mercado capitalista. 
Nesse contexto, segundo Oliveira (2005), o Estado optou por uma lógica capitalista de ocupação do território amazônico, durante a década de 1970, regida através da apropriação privada dos espaços e seus recursos. Ainda segundo o autor, os governos militares acreditavam que os problemas sociais, de fato, eram conjunturais e que poderiam ser atenuados com desenvolvimento regional realizado através da expansão das atividades econômicas.

A forma capitalista de ocupação do território e de desenvolvimento regional adotada pelos governos militares se iniciou através da reestruturação dos órgãos de planejamento regional, como a Superintendência para o Desenvolvimento da Amazônia (Sudam), que foi o principal órgão na viabilização de projetos agropecuários em latifúndios e de grandes áreas mineradoras, realizados por capitais privados estrangeiros ou nacionais, contando com grandes incentivos fiscais e tributários.

Davis ilustra esse contexto e a inclinação dos militares pelo modelo agrário capitalista através do seguinte relato:

No início de 1974, começaram a aparecer os primeiros indícios de que esse modelo se tornaria o padrão básico. [...]

Em setembro de 1974 o governo tornava ainda mais clara sua posição quanto à questão vital da política agrária para a Amazônia. [...] o Governo criaria um novo projeto, chamado Polamazônia, para designar 15 "polos de desenvolvimento" na Amazônia, de modo a estimular uma série de novos empreendimentos de pecuária, mineração e extração de madeira. (DAVIS, 1978, p. 142)

No outro lado da moeda, Oliveira (2005) aponta algumas medidas adotadas pelo Estado durante esse período para abrandar as tensões sociais relacionadas à concentração fundiária por meio da distribuição de pequenas parcelas de terra ao longo da Transamazônica e da concessão de créditos agrícolas a colonos nordestinos provenientes do Polígono das Secas, de forma a estimular o desenvolvimento de policulturas de subsistência. Porém, segundo o autor, essas medidas foram em essência apenas para a criação de "viveiros de mão de obra" que abasteceriam os grandes projetos capitalistas. 
O modelo de ocupação utilizado no Brasil Central e na Amazônia durante as décadas de 1960 e 1970, portanto, basearam-se na criação de grandes propriedades agropecuárias e mineradoras, ligadas ao capital industrial agro-mineral exportador, fomentados por programas governamentais através de incentivos fiscais e tributários. Nas palavras de Ariovaldo Umbelino de Oliveira:

\begin{abstract}
Parte-se, portanto, do princípio de que a abertura das novas frentes de ocupação na Amazônia traz consigo o caráter contraditório da formação da estrutura fundiária brasileira. Ou seja, o processo que leva os grandes capitalistas a investir na fronteira obriga a sua abertura aos trabalhadores do campo. Igual, simultânea e contraditoriamente, o processo que abre acesso aos recursos minerais da região aos grupos econômicos abre-se também aos garimpeiros. (OLIVEIRA, 2005, p. 68)
\end{abstract}

Nessa perspectiva, os principais órgãos de desenvolvimento regional, juntamente com o Banco da Amazônia e o Banco Nacional de Desenvolvimento (BNDES), foram, na frente minerária, os grandes responsáveis pelo aumento exponencial do número de pesquisas e concessões de extração mineral na Região Norte e no Mato Grosso em favor de companhias privadas nacionais e internacionais.

Nesta pesquisa, houve uma tentativa de se mapear a distribuição dos processos minerários referentes a esse período na bacia do rio das Mortes, porém, há hoje uma dificuldade em se rastrear os processos minerários que já foram encerrados ou entraram em caráter de disponibilidade, pois esses processos fatalmente sofreram modificações ao longo do tempo.

Um processo minerário pode entrar em "disponibilidade" ou ser "encerrado" por várias razões. Caso o solicitante da concessão não apresente os pré-requisitos necessários, ele pode perder a prioridade no projeto de extração da área solicitada, que entra em disponibilidade e pode ser requerida por qualquer outra pessoa jurídica que atenda aos requisitos. Porém, quando alguém assume essa área, o processo muda de número e adota-se a data da nova solicitação. Caso isso se repita por várias vezes, fica muito difícil rastrear as solicitações anteriores. 
Por outro lado, se ninguém se interessar pela área "disponível", ou a área não apresentar viabilidade econômica, ou sequer o mineral esperado, esse processo minerário poderá ser encerrado e, se for reaberto anos depois, o novo registro assumirá nova numeração e o processo anterior dificilmente será rastreado.

De qualquer forma, a distribuição atual dos processos é um bom indicativo de qual tipo de pressão a atividade minerária exerceu e continua exercendo sobre as terras Xavante.

A monopolização dos requerimentos minerários nessa área e a proximidade destes com os limites das TI são reflexos das políticas integracionistas implantadas pelos governos militares e, ao mesmo tempo, evidenciam as contínuas tentativas de expansão do capital sobre as Terras Indígenas, realizadas através da ação e presença de grandes empresas mineradoras privadas na bacia.

A maioria dos processos minerários localizados nas imediações das TI Xavantes encontra-se atualmente em fase preliminar - como a de autorização de pesquisa - o que permite a projeção de alguns cenários.

O primeiro é que o início das atividades minerárias na região, mesmo não sendo iminente devido à complexidade variável de cada processo, é latente, em especial, diante da capacidade econômica e influência política que as grandes empresas mineradoras possuem no atual cenário políticoeconômico.

O segundo cenário - um desdobramento do primeiro - se estabelece na possibilidade dessas solicitações serem deferidas simultaneamente ou em intervalos curtos de tempo, já que há um monopólio nas solicitações, o que invariavelmente provocaria um aumento brusco da presença de nãoindígenas no entorno das TI. 
Mapa 2 - Processos minerários na bacia do Alto Araguaia.

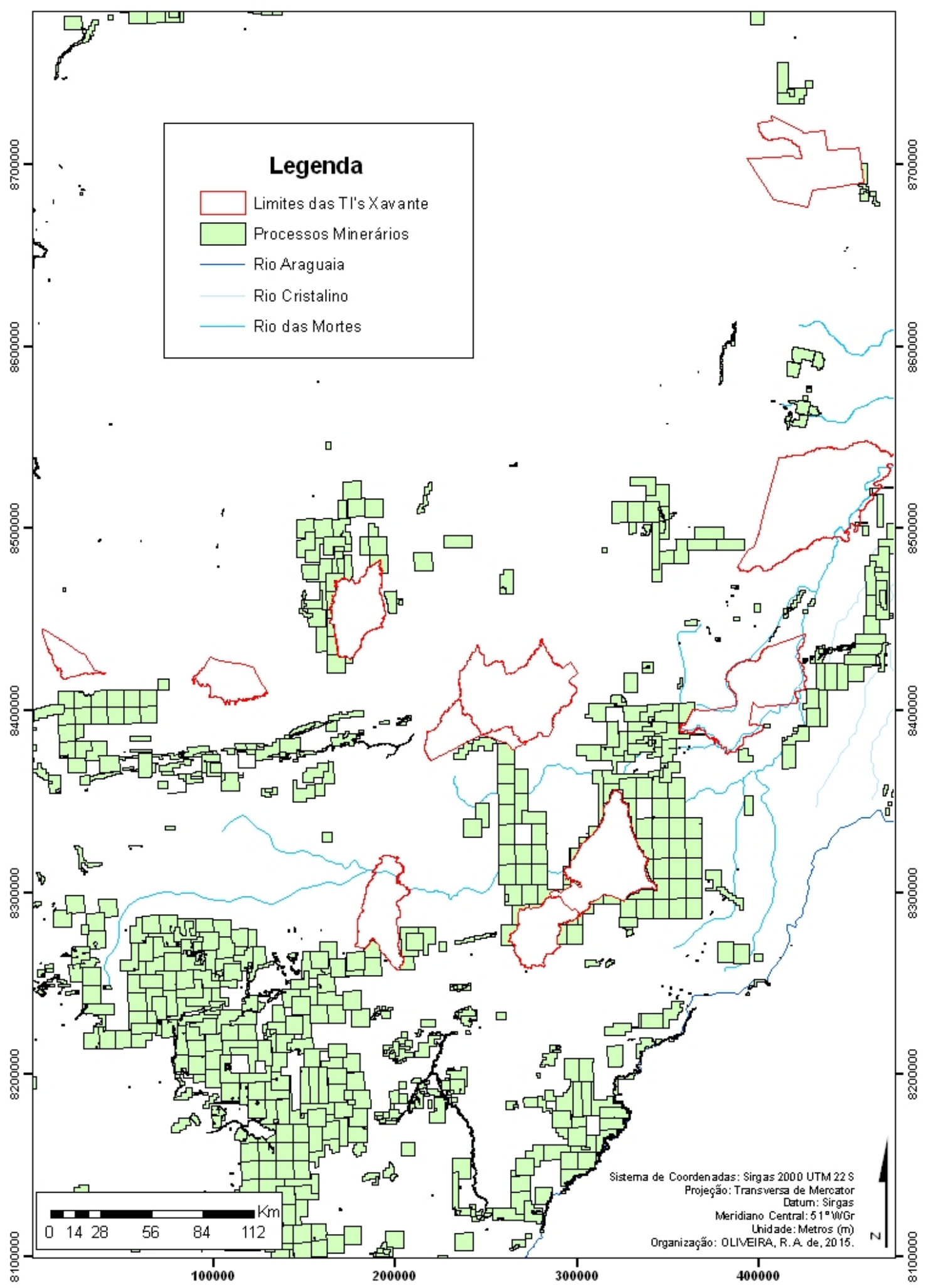

Fonte: DNPM, 2013. 
Tabela 1 - Processo minerários na sub-bacia do rio das Mortes com área superior a 8000 ha.

\begin{tabular}{|c|c|c|c|c|c|c|c|c|}
\hline Proc & Número & Ano & Area em $h$ & Fase do processo & Nome do requerente & Substância & Uso & \\
\hline $866662 / 2009$ & 866662 & 2009 & 8470 & Autorização de Pesquisa & Adher Empreendimentos Ltda. & Minério de Ferro & INDUSTRIAL & MT \\
\hline $866201 / 2011$ & 866201 & 2011 & 9989 & Autorização de Pesquisa & Adher Empreendimentos Ltda. & Minério de Ferro & INDUSTRIAL & MT \\
\hline $866172 / 2011$ & 866172 & 2011 & 9300 & Autorizaçẫo de Pesquisa & Adher Empreendimentos Ltda. & Minério de Ferro & INDUSTRIAL & MT \\
\hline $866193 / 2011$ & 866193 & 2011 & 9980 & Autorização de Pesquisa & Adher Empreendimentos Ltda. & Minério de Ferro & INDUSTRIAL & MT \\
\hline $866176 / 2011$ & 866176 & 2011 & 9993 & Autorizaçẫo de Pesquisa & Adher Empreendimentos Ltda. & Minério de Ferro & INDUSTRIAL & MT \\
\hline $866215 / 2011$ & 866215 & 2011 & 8695 & Autorizaçẫo de Pesquisa & Adher Empreendimentos Ltda. & Minério de Ferro & INDUSTRIAL & MT \\
\hline $866226 / 2011$ & 866226 & 2011 & 9013 & Autorizaçẫo de Pesquisa & Uniẫo Pesquisas Minerais Ltda & Minério de Ferro & INDUSTRIAL & MT \\
\hline $866192 / 2011$ & 866192 & 2011 & 9980 & Autorizaçã̃o de Pesquisa & Adher Empreendimentos Ltda. & Minério de Ferro & INDUSTRIAL & MT \\
\hline $866181 / 2011$ & 866181 & 2011 & 9999 & Autorizaçẫo de Pesquisa & Adher Empreendimentos Ltda. & Minério de Ferro & INDUSTRIAL & MT \\
\hline $866182 / 2011$ & 866182 & 2011 & 9825 & Autorização de Pesquisa & Adher Empreendimentos Ltda. & Minério de Ferro & INDUSTRIAL & MT \\
\hline $866184 / 2011$ & 866184 & 2011 & 9212 & Autorizaçẫo de Pesquisa & Adher Empreendimentos Ltda. & Minério de Ferro & INDUSTRIAL & MT \\
\hline $866170 / 2011$ & 866170 & 2011 & 9983 & Autorização de Pesquisa & Adher Empreendimentos Ltda. & Minério de Ferro & INDUSTRIAL & MT \\
\hline $866195 / 2011$ & 866195 & 2011 & 9985 & Autorização de Pesquisa & Adher Empreendimentos Ltda. & Minério de Ferro & INDUSTRIAL & MT \\
\hline $866204 / 2011$ & 866204 & 2011 & 9994 & Autorizaçẫo de Pesquisa & Adher Empreendimentos Ltda. & Minério de Ferro & INDUSTRIAL & MT \\
\hline $866199 / 2011$ & 866199 & 2011 & 9989 & Autorizaçăo de Pesquisa & Adher Empreendimentos Ltda. & Minério de Ferro & INDUSTRIAL & MT \\
\hline $866185 / 2011$ & 866185 & 2011 & 9766 & Autorização de Pesquisa & Adher Empreendimentos Ltda. & Minério de Ferro & INDUSTRIAL & MT \\
\hline $866202 / 2011$ & 866202 & 2011 & 9994 & Autorizaçã̃o de Pesquisa & Adher Empreendimentos Ltda. & Minério de Ferro & INDUSTRIAL & MT \\
\hline $9 / 2011$ & 866179 & 2011 & 9828 & Autorização de Pesquisa & Adher Empreendimentos Ltda. & Minério de Ferro & INDUSTRIAL & MT \\
\hline & & 2011 & 9975 & Autorizaçã̃o de Pesquisa & Adher Empreendimentos Ltda. & Minério de Ferro & INDUSTRIAL & MT \\
\hline $89 / 2011$ & & 2011 & 9975 & Autorizaçã̃o de Pesquisa & Adher Empreendimentos Ltda. & Minério de Ferro & INDUSTRIAL & MT \\
\hline $866180 / 2011$ & 866180 & 2011 & 9997 & Autorizaçẫo de Pesquisa & Adher Empreendimentos Ltda. & Minério de Ferro & INDUSTRIAL & MT \\
\hline
\end{tabular}

Fonte: DNPM, 2013.

O contexto político e econômico atual difere em vários aspectos daquele produzido durante os governos militares, o que inexoravelmente interfere na atuação das empresas privadas nos dias atuais. Porém, os resultados da inserção forçada de novas áreas e povos na economia a serviço do capital, em essência, produz resultados semelhantes aos ocorridos no passado: conflitos, doenças, estupros, mortes e perdas socioculturais entre os povos indígenas.

\section{Considerações finais}

Hoje, refletir sobre a pressão que a sociedade nacional exerce sobre o rarefeito mosaico de reservas indígenas não se restringe aos resultados que a colonização, que a propriedade privada, que as frentes pioneiras de ocupação, entre tantos outros fenômenos, impuseram aos povos nativos, mas também deve incluir como esses povos têm dialogado com essas mudanças, desenvolvendo diferentes meios e estratégias para a manutenção de sua sobrevivência.

A contramão do processo de expansão capitalista pode se realizar a partir da atuação política das próprias comunidades indígenas que, ao negarem uma legislação que não Ihes favorece, assumem uma posição de 
agentes, não mais de vítimas, suplantando as leis que na prática não têm força para representá-los. Isso pode ser ilustrado a partir das palavras de Latouche:

Sob o rolo compressor da ocidentalização, tudo parece ter sido destruído, nivelado, esmagado, e, no entanto, ao mesmo tempo, os recifes frequentemente estão apenas submersos, resistindo às vezes, e prontos para ressurgir à superfície. (LATOUCHE, 1994, p. 14)

Os povos indígenas, juntamente com vários setores da sociedade nacional, acreditam num caminho alternativo ao da expansão do capital para a sua manutenção física e cultural. Porém, isso só será possível, segundo Martins (1993), através da aceitação do "outro" como "igual".

Melatti (2007) corrobora essa ideia quando afirma que o "branco" deve abandonar antigas visões (românticas, estatísticas, burocráticas, empresariais) e outros pré-julgamentos a respeito dos povos indígenas, para que novas relações possam florescer de maneira mais equilibrada e harmônica.

O reconhecimento efetivo do indígena, do caiçara, do quilombola, do seringueiro, das populações ribeirinhas ou de outras populações tradicionais enquanto populações diversas simboliza o primeiro passo nesse caminho. 0 caminho "alternativo", por isso, não é um caminho "paralelo", ele é a busca pelo reconhecimento do outro como igual, pois só é possível reconhecer a si mesmo enquanto indivíduo-coletivo através do outro.

Em outras palavras, para Martins (1993), a "incapacidade" de se relacionar com o "estranho", fruto da intolerância desenvolvida historicamente, é tão prejudicial quanto o próprio capitalismo, mais que isso, essa intolerância é um dos principais fatores de retroalimentação do capitalismo.

No fim, a mineração realizada próxima ou no interior de Terras Indígenas pode, através do aumento do número de não-indígenas, comprometer a saúde física e cultural desses povos, pois mineradoras e 
A Terra Xavante (mais uma vez) no caminho da mineração, pp. 105-126.

mineradores, além de levarem no seu interior a intolerância ao "outro", não conseguem perceber que, ao consumirem de maneira predatória os recursos desses territórios, estão na verdade cessando uma conexão ancestral e única.

\section{Referências bibliográficas}

Alencastre, José Martins Pereira de. Anais da Província de Goiás. Brasília: Sudeco/Governo de Goiás, 1979 (1863).

CHAIM, Marivone Matos. Aldeamentos indígenas: Goiás, 1749-1811. 2. ed., São Paulo: Nobel; Brasília: INL; Fundação Nacional pró-Memória, 1983.

DAVIS, Shelton. Vítimas do milagre: o desenvolvimento e os índios do Brasil. Rio de Janeiro: Zahar, 1978.

DE PAULA, Luís Roberto. Travessias: um estudo sobre a dinâmica sócioespacial Xavante. São Paulo, 2007. Tese (Doutorado em Antropologia) - FFLCH, USP.

FERNANDES, Bernardo M.; WELCH, Clifford A.; GONÇALVES, Elienai C. Políticas fundiárias no Brasil: uma análise geo-histórica da governança da terra no Brasil. Roma: 2012. Framingthe Debate Series, n 2.

FREIRE, José Rodrigues. Relação da Conquista do Gentil Xavante conseguida pelo Ilmo. Sr. Tristão da Cunha Menezes (1790). Coleção de textos e documentos. São Paulo: FFLCH-USP, 1951.

GIACCARIA, Bartolomeu; HEIDE, Adalberto. Xavante (Auwe Uptabi: povo autêntico): pesquisa histórico-etnográfica. São Paulo: Ed. Dom Bosco, 1972.

GOMIDE, Maria Lúcia Cereda. Maranã Bödödi: a territorialidade Xavante no Ró. São Paulo, 2008. Tese (Doutorado em Geografia Física) - FFLCH, USP.

LATOUCHE, Serge. A ocidentalização do mundo. Petrópolis, RJ: Vozes, 1994.

MARTINS, José de Souza. Expropriação e violência: a questão política no campo. 2. ed., São Paulo: Hucitec, 1982a.

Sobre o modo capitalista de pensar. São Paulo: Hucitec, 1982b.

A chegada do estranho. São Paulo: Hucitec, 1993.

MELATTI, Julio Cezar. Índios do Brasil. São Paulo: Edusp, 2007.

MORAES, Antônio Carlos Robert. Ideologias geográficas. 5. ed., São Paulo: Anablume, 2005. 
OLIVEIRA, Ariovaldo Umbelino de. "BR-163 Cuiabá-Santarém: geopolítica, grilagem, violência e mundialização". In: TORRES, M. (org.). Amazônia revelada: os descaminhos ao longo da BR-163. Brasília: CNPq, 2005.

PRADO JUNIOR, Caio. História econômica do Brasil. São Paulo: Brasiliense, 2008.

RAVAGNANI, Oswaldo Martins. A experiência Xavante com o mundo dos brancos. Araraquara: Edunesp, 1991. 